\author{
Diego Bettucci \\ Lucia Testa \\ Silvia Calzoni \\ Paola Mantegazza \\ Michele Viana \\ Francesco Monaco
}

\section{Combination of tizanidine and amitriptyline in the prophylaxis of chronic tension-type headache: evaluation of efficacy and impact on quality of life}

Received: 15 July 2005

Accepted in revised form: 7 October 2005

Published online: 15 December 2005
D. Bettucci $\bullet$ L. Testa $\bullet$ S. Calzoni

P. Mantegazza $\bullet$ M. Viana $\bullet$ F. Monaco

Headache Centre,

Department of Neurology,

University "Amedeo Avogadro",

Corso Mazzini 18, I-28100 Novara, Italy

e-mail: diego.bettucci@maggioreosp.novara.it

Tel.: +39-0321-373-3747

Fax: +39-0321-373-3298

\begin{abstract}
Chronic tension type headache $(\mathrm{CTTH})$ has a strong impact on the Quality Of Life (QOL). We carried out an open-label randomized clinical trial on 18 patients with CTTH in order to compare two different regimens of pharmacological prophylaxis: the first provided for the use of amitriptyline $20 \mathrm{mg} / \mathrm{d}$ during 3 months, while in the second we combined amitriptyline with tizanidine $(4 \mathrm{mg} / \mathrm{d})$ in the first 3 weeks of treatment.

Our hypothesis is that the combination therapy may guarantee an improvement of QOL even in the early stages of treatment. In fact, it's as well-known, there is a delay of 2-3 weeks in the prophylactic effect of amitriptyline, with a consequent persistence, in the first phases of therapy, of the headache and its negative impact.

We assessed the following outcome
\end{abstract}

measures: frequency, pain intensity, duration of headache and the Headache Impact Test (HIT) score, used as headache-related QOL measure. The combination therapy was effective since the first month of treatment, with a significant reduction of the headache, greater than one obtained with amitriptyline alone, in terms of frequency $(-52,3 \%$ vs. $-40,7 \%)$, intensity $(-59,51 \%$ vs. $-20,39 \%)$ and duration $(-53,17 \%$ vs. $-36,16 \%$ ).

This trend was confirmed by the HIT. Our data suggest that the combination of tizanidine with amitriptyline is faster than the amitriptyline alone in providing an improvement in the headache pattern and correlated QOL.

Keywords Chronic tension-type headache • Tizanidine • Amitriptyline • Quality of life • Prophylaxis

\section{Introduction}

It is well known that chronic headaches, of which the tension-type form is the one with the greatest epidemiological prevalence [1], have a strong impact in terms of "Quality Of Life" (QOL) and socio-economic costs [2].

At present, amitriptyline represents the first choice in prophylactic therapy of chronic tension-type headache (CTTH), supported by the highest levels of evidence [3].
As is well known, the effectiveness of amitriptyline in CTTH prophylaxis may be observed only after 2-3 weeks of therapy, with a consequent persistence of the headache and its correlated negative impact on psychophysical conditions in the first phases of treatment. In this respect, a faster pharmacological treatment would be very useful.

Many clinical trials indicate tizanidine as a promising additional prophylactic agent in chronic headaches, while currently available data do not justify its use in monotherapy [3, 4]. Tizanidine is an $\alpha 2$ agonist that inhibits the 
release and effect of norepinephrine in both the brainstem (e.g., locus coeruleus) and the spinal cord. It acts as a central muscle relaxant but it also has an antinociceptive effect that does not involve the endogenous opioid system and appears to be centrally mediated by $\alpha 2$ adrenoreceptors, with little, if any, interaction with 5-HT, dopamine and GABA receptors [4].

There is not a codified posology for headache prophylaxis with tizanidine. In clinical trials it was used at a dosage between 2 and $24 \mathrm{mg} /$ day, for periods varying from 2 to 12 weeks [5-7]. Unlike amitriptyline, tizanidine does not have a latency period of clinical effects, neither as an antispastic nor in the prophylaxis of cephalalgia [4].

We carried out an open-label clinical trial in order to evaluate the effectiveness and the impact on QOL of a combined treatment with tizanidine and amitriptyline in the first weeks of the pharmacological prophylaxis of CTTH. The aim of our study was to determine if the combination tizanidine/amitriptyline may have, as expected from a pharmacodynamic standpoint, a faster action than amitriptyline alone in both reducing the cephalalgical pattern, and consequently, in improving the headache-related QOL.

\section{Patients and methods}

All consecutive patients $(n=27)$ who had been diagnosed with CTTH according to the International Headache Society criteria in the six months prior to the study were preliminarily evaluated. Subjects with coexistence of migraine (IHC criteria) and CTTH were excluded. After an observation period of one month, in which patients recorded their headache pattern in a baseline standard diary, 18 patients $(5 \mathrm{M}, 13 \mathrm{~F}$, mean age $35.2 \pm 11)$ were enrolled in the study. All patients had normal neurological examination and laboratory investigation. They did not show any other health problems, or contraindications to the use of the drugs in question. Depression had been ruled out at the time of recruitment using the Zung test. Abortive treatment with a simple analgesic was permitted, but we excluded the abusers (IHC criteria) [8]. The symptomatic drugs used in our population were paracetamol and nonsteroidal anti-inflammatory drugs, with a mean use of abortive medication of $11.15 \pm 3.49$ days/month in the observation period.
Patients at the run-in were randomized, via an online random number generator (http://www.randomizer.org), into two groups of treatment, each one consisting of 9 patients. The first (A group, 2M, $7 \mathrm{~F}$, average age $34.5 \pm 12.2$ ) assumed amitriptyline $20 \mathrm{mg} /$ day for 3 months, while the second (B group, $3 \mathrm{M}, 6 \mathrm{~F}$, mean age $36 \pm 9.8$ ) was treated with amitriptyline $20 \mathrm{mg} /$ day for 3 months combined with tizanidine ( $4 \mathrm{mg} /$ day) in the first 21 days of treatment.

Using a standard headache diary/4 weeks, drawn up by the patient, we collected the following outcome measures: number of headache days per month, pain intensity with a numerical score $(1$, mild headache, easily ignored; 2 , moderate, tolerable; 3 , very intense pain/intolerable) and duration of headache in hours. The headache-related QOL was assessed monthly with the HIT6 questionnaire [9].

In both groups, monthly headache frequency, mean intensity, mean headache duration and HIT scores were assessed using data from standard headache diary/4 weeks of both pre-treatment month (T0 period - baseline) and two treatment periods (weeks 1-4 [T1 period] and weeks 9-12 [T2 period]).

For each group of treatment, we assessed the mean per cent reduction of each variable obtained in $T_{1}$ and $T_{2}$ evaluation with the mean baseline value. Thereafter we compared the results in the two treatment groups. Statistical evaluation was performed with the $\chi^{2}$-test, deeming a $p$ value $<0.05$ as significant.

\section{Results}

All 18 patients enrolled completed the study. In our patients the combination therapy (B group: tizanidine+amitriptyline) was effective from the first month of treatment, with a significant reduction of symptoms $(>50 \%)$ in terms of frequency, intensity and duration of the headache. This reduction was greater than the one obtained with amitriptyline alone (A group).

In particular, in the first four weeks of treatment we recorded the following per cent improvement in headache indexes (Tables 1 and 2): frequency $-52.3 \%$ in B group $v s$. $-40.7 \%$ in A group $(p<0.05)$, intensity $-59.51 \%$ vs. $-20.39 \%$ $(p<0.02)$, duration $-53.17 \%$ vs. $-36.16 \%(p<0.05)$. At the end of the 90-day treatment period, however, there were no significant differences (frequency $-57.71 \%$ in B group $v s$. $60.04 \%$ in A group; intensity $-30.05 \%$ vs. $-23.81 \%$; and duration $-56.55 \%$ vs. $-37.55 \%$; all results with $p>0.05$ ).

Table 1 Results of prophylaxis with amitriptyline alone

\begin{tabular}{lrrrr}
\hline Group A: amitriptyline & $\begin{array}{r}\text { Mean headache, } \\
\text { days/4 weeks } \pm \text { SD }\end{array}$ & $\begin{array}{c}\text { Mean pain, } \\
\text { intensity } \pm \text { SD }\end{array}$ & $\begin{array}{r}\text { Mean duration, } \\
\mathrm{h} \pm \text { SD }\end{array}$ & $\begin{array}{r}\text { HIT, } \\
6 \pm \text { SD }\end{array}$ \\
\hline $\mathrm{T}_{0}$ & $20.32 \pm 3.43$ & $1.68 \pm 0.19$ & $6.95 \pm 3.05$ & $61.26 \pm 2.46$ \\
$\mathrm{~T}_{1}$ & $12.05 \pm 3.59$ & $1.34 \pm 0.26$ & $4.44 \pm 2.25$ & $53.37 \pm 2.57$ \\
$\mathrm{~T}_{2}$ & $8.12 \pm 3.63$ & $1.28 \pm 0.51$ & $4.34 \pm 2.36$ & $47.71 \pm 15.28$ \\
Mean improvement \% $\left(\mathrm{T}_{0}-\mathrm{T}_{1}\right)$ & $-40.70 \%$ & $-20.39 \%$ & $-36.16 \%$ & $-12.88 \%$ \\
Mean improvement \% $\left(\mathrm{T}_{0}-\mathrm{T}_{2}\right)$ & $-60.04 \%$ & $-23.81 \%$ & $-37.55 \%$ & $-22.11 \%$ \\
\hline
\end{tabular}


Table 2 Results of use of tizanidine in addiction to amitriptyline

\begin{tabular}{|c|c|c|c|c|}
\hline Group B: amitriptyline+tizanidine & $\begin{array}{r}\text { Mean headache, } \\
\text { days/4 weeks } \pm \text { SD }\end{array}$ & $\begin{array}{r}\text { Mean pain, } \\
\text { intensity } \pm S D\end{array}$ & $\begin{array}{r}\text { Mean duration, } \\
h \pm S D\end{array}$ & $\begin{array}{r}\mathrm{HIT}, \\
6 \pm \mathrm{SD}\end{array}$ \\
\hline $\mathrm{T}_{0}$ & $21.80 \pm 4.76$ & $1.83 \pm 0.28$ & $8.05 \pm 2.79$ & $62.50 \pm 3.41$ \\
\hline $\mathrm{T}_{1}$ & $10.40 \pm 5.89$ & $1.29 \pm 0.37$ & $3.77 \pm 2.00$ & $50.90 \pm 3.54$ \\
\hline $\mathrm{T}_{2}$ & $9.22 \pm 7.00$ & $1.28 \pm 0.51$ & $3.49 \pm 2.47$ & $48.00 \pm 6.32$ \\
\hline Mean improvement $\%\left(\mathrm{~T}_{0}-\mathrm{T}_{1}\right)$ & $-52.30 \%$ & $-59.51 \%$ & $-53.17 \%$ & $-18.56 \%$ \\
\hline Mean improvement $\%\left(\mathrm{~T}_{0}-\mathrm{T}_{2}\right)$ & $-57.71 \%$ & $-30.05 \%$ & $-56.65 \%$ & $-23.20 \%$ \\
\hline
\end{tabular}

This trend of improvement had also been confirmed by the pattern of HIT scores, which are an indicator of the headache impact on QOL (-18.56\% vs. $-12.88 \%$ in T1 period, $p<0.05$; at the 3rd month -23.20 vs. $-22.11, p>0.05$ ).

Three patients $(33.3 \%)$ from group A and four patients (44.4\%) from group B reported mild to moderate common adverse events such as somnolence $(22.2 \%, n=2$ in A group and $33.3 \%, n=3$ in B group), asthenia (11.1\%, $n=1$ in A group and $22.2 \%, n=2$ in B group), dry mouth (2 patients, $22.2 \%$ in A group) and dizziness (only 1 patient, $11.1 \%$ in B group).

\section{Discussion}

Our data, although obtained from a small group of patients, suggest that adding tizanidine to amitriptyline in the first phase of treatment provides a more rapid improvement in the headache pattern, compared to the use of amitriptyline alone. As expected, the faster effectiveness of combination therapy had an immediate impact on the headache-related quality of life. Furthermore, the use of tizanidine in addition to amitriptyline was well tolerated.

In our opinion, the high frequency and the remarkable disability correlated with CTTH suggest the need for a prophylaxis treatment which is not only effective, but also as fast as possible in restoring an acceptable QOL from the first days of treatment.

This preliminary study suggests that the combination of amitriptyline and tizanidine has a promising potential as a therapeutic option in the preventive treatment of CTTH. A large double-blind randomised controlled trial would be needed in order to draw strong evidence on this issue.

\section{References}

1. Millea PJ (2002) Tension-type headache: a review. Am Fam Physician 66[Suppl 5]:797-804

2. Rasmussen BK, Jenesen R, Olesen J (1992) Impact of headache on sickness absence: a Danish population study. J Epidemiol Community Health 46:443-445

3. Goadsby P (2002) Management of chronic tension-type headache. Clin Evid 7:1145-1152

4. Freitag FG (2003) Preventive treatment for migraine and tension-type headache: do drugs having effects on muscle spasm and tone have a role? CNS Drugs 17[Suppl 6]:373-381
5. Saper JR, Lake AE, Cantrell DT, Winner PK, White JR (2002) Chronic daily headache prophylaxis with tizanidine: a double-blind, placebo controlled, multicenter outcome study. Headache 42:470-482

6. Fogelhom R, Murros K (1992) Tizanidine in chronic tension-type headache: a placebo-controlled doubleblind cross-over study. Headache 32:509-513

7. Shimomura T, Awaki T, Kowa K, Takahashi H (1991) Treatment of tension-type headache with tizanidine hydrochloride: its efficacy and relationship to the plasma MHPG concentration. Headache 31:601-604
8. Headache Classification Subcommittee of the International Headache Society (2004) The international classification of headache disorders, 2nd edn. Cephalalgia 24[Suppl 1]:1-160

9. Whare J, Bayliss M, Diamond M, Teppert S et al (2000) Measuring the impact of migraine and severe headache with the HIT. Neurology 54[Suppl 3]:336-453 